\title{
Revisiting the mechanisms for cellular homeostasis and electrophysiological responses: Classical membrane theory, association-induction hypothesis and murburn concept
}

\author{
Kelath Murali Manoj ${ }^{1} * \&$ Hirohisa Tamagawa ${ }^{2} *$ \\ (*Corresponding authors) \\ ${ }^{1}$ Satyamjayatu: The Science \& Ethics Foundation, \\ Kulappully, Shoranur-2 (PO), Palakkad District, Kerala State, India-679122. \\ Email: murman@satyamjayatu.com \\ ${ }^{2}$ Dept. of Mechanical Engineering, Gifu University, \\ 1-1 Yanagido, Gifu City, Japan 501-1193. \\ Email: tmgwhrhs@gifu-u.ac.jp
}

\begin{abstract}
Pursuits in modern cellular physiology are fraught with disagreements on the physicochemical explanations for how a cell coordinates the core aspects of its life-sustaining activities. While the membrane theory of homeostasis deems the cell-membrane and the proteins embedded therein as the chief players, the association-induction (or sorption/bulk-phase) theory deems the protoplasm (the aqueous phase of dissolved proteins) as the key determinant of cellular composition and inflow-efflux of key molecules/ions. In the first school of thought, transmembrane potential and protein conformations are deemed as key operative principles whereas in the latter theory, sorption-desorption dynamics and re-arrangements of bulk phase determine outcomes. In this exploration/analysis, we first present an unbiased collection of the pertinent founding concepts and viewpoints in the field of cellular homeostatic and responsive mechanisms (that do not invoke genetic-level interventions/regulations). Further, several critical queries are posed that seek us to explore concepts beyond the existing beliefs in homeostatic electrophysiology, for arriving at more holistic solutions. In particular, the discussion focuses on the basic information available on charge/ion differentials of the simple cellular systems and how cells achieve the disparity in the distribution of monovalent and divalent cations, as per the order: $\mathrm{K}^{+}>\mathrm{Na}^{+}>\mathrm{Mg}^{2+}>\mathrm{Ca}^{2+}$. It is suggested that murburn concept (molecule-unbound ion-radical interactions) could be relevant in this quest. Energy metabolism-based outcomes (murburn equilibriums) and the dissolved-phase proteins' innate ability to bind/adsorb ions selectively are projected as the integral rationale for the observed phenomenon.
\end{abstract}

Keywords: homeostasis; resting/trans membrane potential; action potential; Hofmeister series; membrane channels; electrogenic pumps; association-induction hypothesis; murburn concept 


\section{Contents}

\section{Introduction: The aspect of life explored}

2. Methods: The approach (ideas and systems) chosen for this explorative study

3. Results: The two contrasting views on homeostasis and cellular responses

I. Membrane theory

II. Association-induction hypothesis (AIH)

\section{Discussion: Analysis and Solutions}

I. Critical analysis of the classical perspectives (membrane theory and AIH)
A. Numbers and types of ions/molecules involved
B. Source/relevance of ionic differential and trans-membrane potential (TMP)
C. Signal transductions: intertwining of homeostasis and TMP
D. Cell volume and surface area: the question of water flux
E. The mechanism of voltage-generation and voltage-gating
F. The 'maverick' cellular dose response formats
$G$. The enigma of salutatory progression (relay of action potential) in neurons
H. Miscellaneous unresolved issues

II. Murburn perspectives and solutions

\section{Conclusion}




\section{Introduction: The aspect of life explored}

As the organized cellular biological whole manifests qualities greater than the sum of its chemico-physical components, life remains an enigma in the gestalt perspective. However, the phenomena of life can be studied well in differentiated detail and integrated holistically, at both molecular and macroscopic levels. To our understanding, life is built on/around three key biological principles- (i) Cell/protoplasm theory of composition: cell/protoplasm is the fundamental unit of life; (ii) Capacity for dynamic sustenance: cells and multicellular living organisms generate energy to do useful work, homeostasize, respond to stimuli and possess adaptability for survival (towards immediate environmental and long-time evolutionary pressures, in terms of changes within their lifetimes and/or through several generations); \& (iii) Central dogma of functional perpetuation: within cells, genes code for proteins and these two together govern a living being's traits. This write-up is a critical exploration for the explanations of the physico-chemical foundations of homeostasis and immediate physiological response to stimuli, involving the intricately associated phenomena of trans-membrane potential (TMP). In particular, Living beings possess unique abilities to concentrate ions within, and this facet is necessary for discharging the essential/vital functions. The long-standing conundrum of how living cells possess unique abilities to concentrate cations in the distribution order of $\mathrm{Na}^{+}>\mathrm{K}^{+}>$ $\mathrm{Mg}^{2+}>\mathrm{Ca}^{2+}$ is addressed, from an ab initio perspective.

\section{Methods: The approach (ideas and systems) chosen for this explorative study}

In the multi-cellular organisms, various tissues (comprising of diverse differentiated cells), organs, organ systems, etc. are integrated and 'administered' with genetic cues/controls, cellular messengers, hormonal, neuronal and other mechanistic measures. Regardless of the complexities in reception of stimuli, it can be envisaged that in order to effectively transduce and synchronize various processes and govern life, certain chemico-physical operating principles must function at multiple levels. Herein, we deal with such direct and simple operating principles (sans genetic/neuronal/hormonal intervention) involved in the maintenance (homeostasis) or fluctuations (response to stimuli) of key components' concentrations within cell(s) and discuss the electrophysiological phenomena associated with the same. 
In spite of its enucleated and therefore, non-replicable and immutable features (and thus, failure to meet the criteria of being termed as a fully functional "living cell"), the pseudo-alive erythrocytes or red blood corpuscles (RBC) can be taken as a simple system for understanding homeostasis. Further, the RBCs can be studied in isolation and they don't have complexities introduced by genetic regulations and mitochondrial metabolism. Neurons, although cannot divide, are definitely classified as 'living cells' by all scientists. In order to deduce and prioritize the key operational principles of homeostasis, we shall peruse the known facts/aspects of the two aforementioned systems. At the very outset, we disclaim that it is merely for the sake of convenience that a distinction is made between homeostasis and response to stimuli. It is quintessential from the laws of physics that the sustenance of life dictates the dynamic maintenance of a "status-quo" (homeostasis) and therefore, it is only consequential that a change results within, in response to perceptible stimuli presented to the living system. Further, quantitative values (whether normal or average) that portray healthy physiology are cited from credible literature. We aim to highlight and/or probe only stark differences, via measurable/quantitative yardsticks. The consensus distribution of major ions in human erythrocytes and serum, earlier compiled from various reliable sources was perused. Solubility of various salts in water at $20{ }^{\circ} \mathrm{C}$ were availed from CRC Handbook of Chemistry and Physics (and Wikipedia) and analyzed with simple mathematical operations to see if there existed any simple and tangible correlations existed between them.

\section{Results: The two contrasting views on homeostasis and cellular responses}

I. As per the acclaimed membrane theory perspective, cellular homeostasis (and consequentially the trans-membrane potential, TMP, whether in resting or activated state) is primarily governed by the cell membrane. This is achieved by regulating the molecules' and ions' traffic across the membrane. Based on the suggestions of pioneers like E Overton, A Nathansohn, J Danielli, etc., Singer and Nicholson developed the proposal of a phospholipid fluidic bilayer membrane with embedded proteins (which, in turn, serve as channels or pumps for various ions) and this became the preferred perception of modern biologists (Alberts et al., 2002; Berg et al., 2002; Nelson \& 
Cox, 2004; Voet \& Voet, 2011). At the resting stage, cells are characterized by a preferential distribution of certain solutes. For example- $\mathrm{RBC}$ has more $\mathrm{K}^{+}$ions inside compared to $\mathrm{Na}^{+}$, whereas the concentration is reversed in the serum (that is- the serum has more $\mathrm{Na}^{+}$compared to $\mathrm{K}^{+}$). As per the membrane theory, the main vectorial agents regulating the concentrations (or disparity) of ions within the cell are passive ion-channels/porters and active ion-pumps/porters. The former are concentration gradient or diffusion based directional pores in the membrane that may be of the leak-type (always open) or gated-type (regulated by ligand-binding or by cues based on mechanical/voltage stimuli). The latter expend energy and serve as electrogenic pumps that move or exchange specific ions against their concentration gradients. In this view, expenditure of energy for functioning ion-pumps indicates a key definition of life. ATP is known as a source of energy that cells need for activating ion-pumps. The difference(s) of concentrations of various ions across the membrane (and the charge disparity that results thereof) is considered as the primary source of TMP, which is in turn deemed to be the operative agent of bringing about a response in the cell. That is, TMP generation and its fluctuations result as a consequence of trans-membrane ion transport. Particularly, cations are deemed responsible for the charge differential across membranes, as exemplified by the mitochondrial membrane potential, which is believed to result due to the working of proton pumps (Alberts et al., 2002; Berg et al., 2002; Nelson \& Cox, 2004; Voet \& Voet, 2011). Hence, in this school of thought, the TMP is directly connected to trans-membrane ion transport. The perspectives and components of this theory are depicted in Figure 1. 


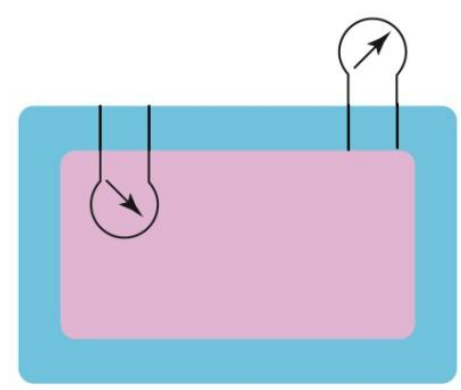

QUANTITATION

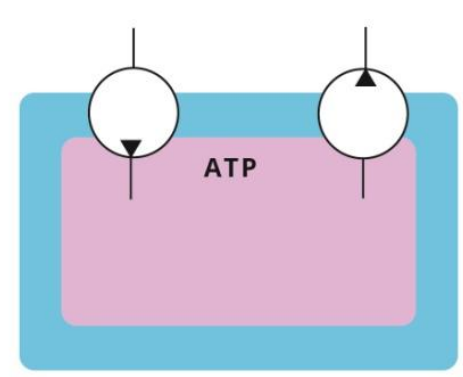

PUMP

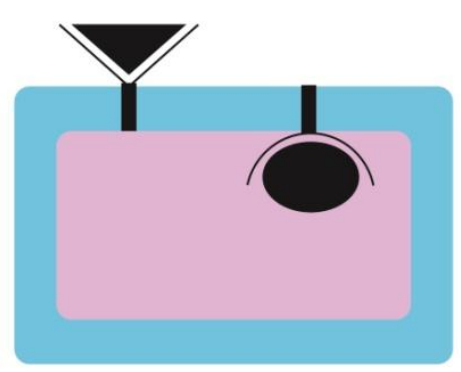

RECOGNITION

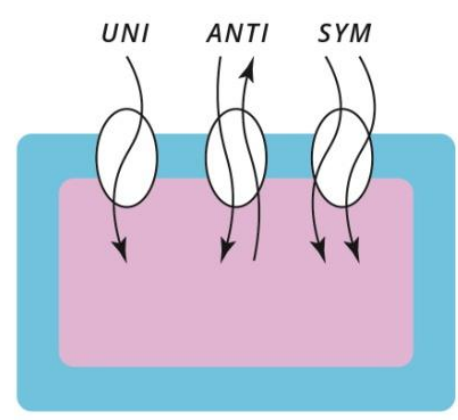

PORTER

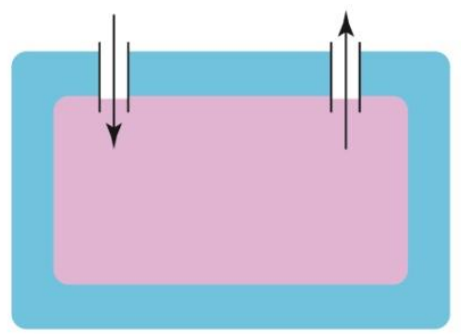

TRANSLOCATION

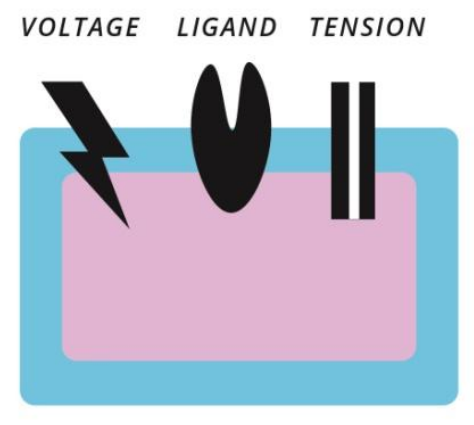

PORE

Figure 1: Components of the membrane theory of cellular electrophysiology

In this view, the membrane and the embedded proteins (including pumps, carriers/porters, channels/pores, etc.) therein are "intelligent systems" that estimate, recognize and translocate various solutes and thus regulate the influx or efflux of components to and from the cell, resulting in homeostasis and electrophysiology. As shown in Figure 1, the active transport process utilizes ATP. There could be active or passive unidirectional porters (e.g. glucose transport in erythrocytes) or symporters (e.g. amino acids' transport in cells lining the intestine) or antiporters (e.g. the ' $3 \mathrm{Na}^{+}$out and $2 \mathrm{~K}^{+}$in' pump of neurons). The membrane channels could be constitutively open (leak type) or be gated by voltage, ligand-binding or tension based mechanisms. Most of these functions involve deterministic changes in conformations of the pertinent membrane proteins along vitally chartered pathways (Alberts et al., 2002; Berg et al., 2002; Nelson \& Cox, 2004; Voet \& Voet, 2011).

II. As per the marginalized sorption or association-induction hypothesis (AIH), electric potential is generated due to adsorption of ions by proteins within a thin layer on cell surface and 
this sorption process could also be affected by the presence of ATP. In this theory, upon binding as a cardinal ligand, ATP could alter protein conformation, which could in turn change its ion adsorption features. In this school of thought, water is also supposed to play a major role in organizing the proteins and ions within the cytoplasm (Ling, 1962, 1973, 1992, 1997). Ion sorption is a phenomenon well-established in living and non-living systems, and is governed by mass action law. Apart from bioscience, spontaneous induction of action potential-like potential spike induction in nonliving system is a widely known experimental fact in nonlinear physics research field. Yoshikawa group's works commissioned in 1980s are typical examples in this regard (Yoshikawa \& Matsubara, 1983; Yoshikawa et. al., 1984, 1985, 1986a,b, 1988; Toko et al., 1985; Nakajo, 1990). Some mathematical models successfully explain such phenomena which are similar to action potential generation. Even in electrochemical research field, similar phenomena have been observed repeatedly (Flasterstein, 1966a,b; Kish et. al., 2000). For example, some metal surface potential exhibits a time-dependent potential spike, when it is submerged in electrolytic solution. Therefore, Ling's theory implicates that the potential generation can take place at surfaces/interfaces even in nonliving systems. This consequence directly contradicts the fundamentals of major school of thought that the membrane potential generation is the consequence of a 'living activity' of the cell. The advocators of the sorption based theory claim that cytoplasmic solution or suspension (of various proteins, biopolymers, organics and ions) can be taken as an electrolyte system, subjected to various adsorption processes. Such systems are known to develop electrical layers (Helmholtz or Gouy-Chapman, for example) across several physical inter-phases (Ling, 1962, 1992, 1997; Kitahara, \& Watanabe, 1984; Brett \& Brett, 1993; Bockris \& Khan, 1993). Adsorptive localization of ions in such layered systems can be envisaged as facile processes enabled by 'tethering' of unbound ions by fixed protein counter-charges, as illustrated in Figure 2. 


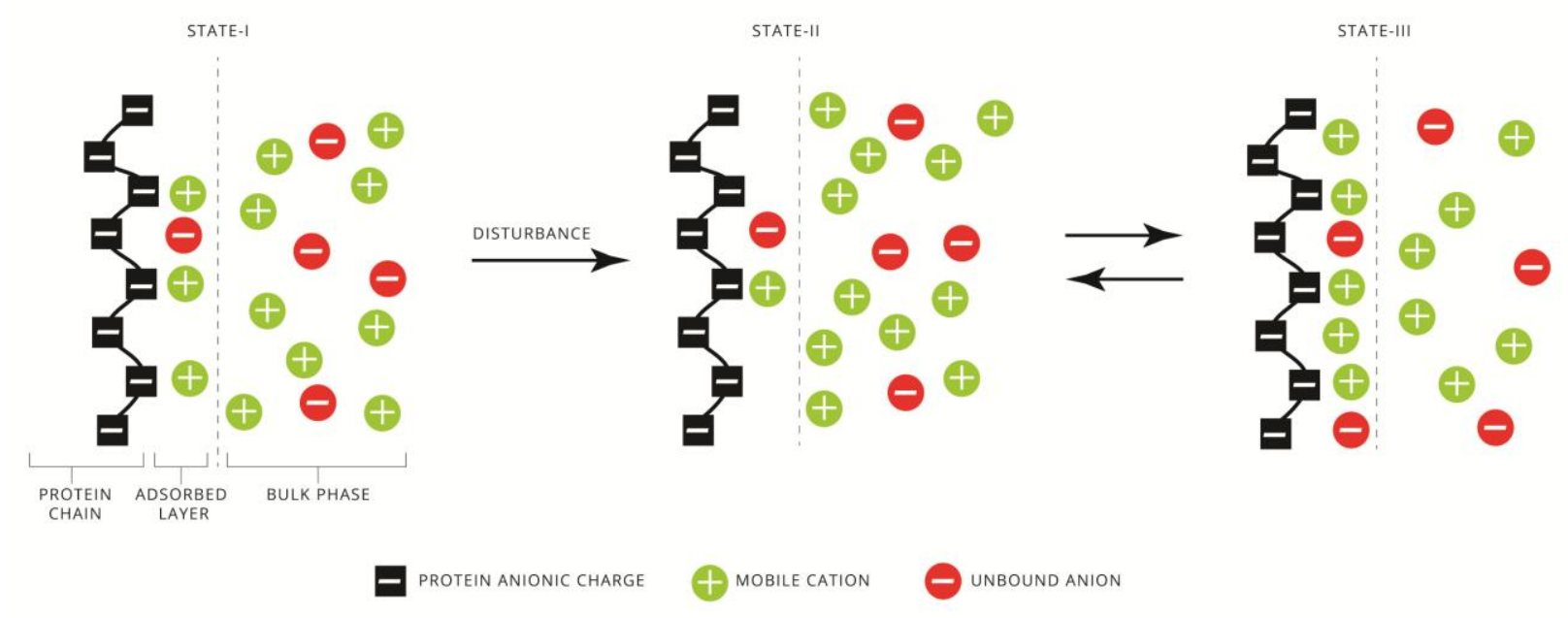

Figure 2: Basics of bulk-phase or association-induction theory of electrophysiology

If some cations are in the adsorbed state while the rest of them are in the free state, then assuming an equilibrium, the constant $K_{e q}$ is given by $K_{e q}=[\mathrm{AB}] /\left[\mathrm{A}^{+}\right]\left[\mathrm{B}^{-}\right]$. Such a cell system would de facto maintain the equilibrium by mass action law or fundamental thermodynamics. That is, at a given temperature, if the concentration of $\mathrm{A}^{+}$and $\mathrm{B}^{-}$somehow deviates from the equilibrium, the cellular system tends to re-attain the equilibrium, given that an intrinsic association-dissociation property exists between the protein and ions. This can be understood from the depiction in Figure 2. Initially the cell is in State-1, the resting phase, wherein the immobile anions of protein and the mobile cations is established only at the immediate neighbor of protein chain. Most of mobile ions in the bulk phase have little to do with such an interaction. Once the external disturbance is exerted on this system, some of adsorbed cations are desorbed as depicted in State-2. The desorbed cations move into the bulk phase, resulting in an excess positive charge or a destructuring of bulk phase water, causing a reorganization of ions at the immediate neighborhood of protein chain. If the excess amount of both mobile cations and anions moved into the protein's immediate neighborhood (as depicted in State-3), it would result in a return to State-2. This alternation of State-2 and State-3 could cause the action potential pulse train, and the system gradually comes to reach the initial state, wherein the action potential ceases. Therefore, the action potential generation could merely be a consequence of autonomous achievement of 'homeostatic equilibrium' by life systems. This is primarily seen as a simple physico-chemical outcome and not necessarily as an "activated" process. 


\section{Discussion: A critical review and prospective solutions}

Having summated the standing perspectives, it is opportune to find faults/lacunae in the explanations, for the advancement of science.

\section{Critical queries and analysis of classical perspectives}

Without delving deeply into the evidence quoted to support the existing viewpoints, we pose some queries that are of fundamental nature, that question the qualitative and quantitative limits of the two proposals. This exercise is driven by the belief that ideas mooted and rooted more than half a century back should reconcile with the awareness brought out in later times.

\section{A. Sheer magnitude of the types and number of ions/molecules and the energy terms involved:} It is known that any given cell must 'instantaneously' regulate at least several hundreds of molecules' (various organics belonging to the classes of amino/organic/nucleic acids, fats/lipids, proteins, carbohydrates, etc.) and a few decades of ions' (like sodium, potassium, magnesium, calcium, chloride, carbonate, phosphate, etc.) concentrations within the cell. It is very difficult to imagine that each of these solutes is quantitatively assessed with preferential binding mechanisms and channels/pumps on the plasma membrane. If a few such receptors or channels or pumps on the membrane did exist for each type of molecule/ion, how could they dynamically regulate the massive amounts of molecules/ions that would equilibrate in and out of the cell? It is elementary to imagine that the total binding surface of the proteins on the membrane would be far lower than the total surface area of the proteins dissolved within the aqueous milieu. Also, the qualitative detection and quantitative estimation of concentrations of various solutes at the membrane would need hitherto unknown mechanisms for each of the molecules and ions involved. Further, estimations show that maintaining these solutes' concentrations (particularly, by $\mathrm{Na}^{+} / \mathrm{K}^{+}$-ATPase) against their gradients would require humongous amounts of ATP, which cannot be supported by the cellular metabolic/energetic machinery (Ling, 1992, 1997). If we submit to the acclaimed physiological perspective, the law of the conservation of energy must be 
violated to maintain the physiological concentrations of various solutes and ions. How could such a weird state of physiology originate, sustain and evolve? On the other hand, while AIH is relatively acceptable with respect to energetics, it cannot explain the selectivity of intake or outflow of several ions and molecules, when compared to the membrane theory. Therefore, both proposals have their strengths and weaknesses within the context of explaining ionic differentials.

\section{B. The source and relevance of ionic differential and trans-membrane potential (TMP): Trans-} membrane potential has always been considered as an outcome of trans-phase ionic movements or interface ionic adsorption, which is the classical Buetner-Baur feud (Colacicco, 1965). The acclaimed biological theory attributes TMP generation to trans-membrane ion transport, at the expense of energy. They also maintain that this potential is capable of doing useful work, like ATP synthesis. However, there are several violations of known principles of chemico-physics and experimental information available till date, and a few are listed below.

(i) Interfacial ion adsorption-desorption processes must have influence on the generation of TMP across phases/interfaces. The ion sorption phenomenon is not taken into consideration in the membrane theory at all, although it is undoubtedly an established phenomenon (coming under the purview of the law of mass action), known to occur in both living and nonliving systems.

(ii) Most intracellular milieus have a higher concentration of potassium ions in comparison to

sodium ions. While both sodium and potassium ions have a unit positive charge $\left(1.602 \times 10^{-19}\right.$ Coulombs), potassium ions have a greater size and mass. From the Hofmeister or lyotropic series, it can be noted that $\mathrm{K}^{+}$ions have a greater propensity to salt out proteins, when compared to $\mathrm{Na}^{+}$ ions. Therefore, this effect signifies that the ions are not mere "mass points" but they have different hydration characteristics and preferential interactions with proteins. The differential adsorption affinities of various ions (to proteins) and the hydration-shell characteristics of the nano-pools of water (Ling, 1962, 1992, 1997; Mentre, 1995, Pollack, 2001, Edelman, 2005; Matveev, 2017; Tamagawa, 2018; Tamagawa \& Ikeda, 2018; Tamagawa et al., 2019) are not considered in the acclaimed explanations. Consequentially, the "activity" (or functional 
concentration) of ions, a feature that physical chemists have used for long, is altogether missing in theoretical treatments of 'electrolytic biological solutions' or homeostasis.

(iii) While electrogenic pumps are believed to be the source of TMP in certain organelles and plant/fungal cells, passive ion movements (particularly, of $\mathrm{K}^{+}$ions) are supposed to make more significant contributions in the animal cells (Alberts et al., 2002). Na-pumps are altogether absent in several plant systems (Pedersen \& Palmgren, 2017). So, how do these cells homeostasize and how come cells don't have ubiquitous/simple physico-chemical logic for such a fundamental phenomenon, one that could form a plank for evolutionary processes?

(iv) It is obvious that the cell components should be theoretically viewed as an electrolytic matter in a 'thermodynamically and probabilistically realistic' state. In this regard, the concentrations of various ions for two animal cell types are given in Table 1. It is known that the membrane potential of resting cells or organelles can range from a few millivolts to even a couple of hundred millivolts, with the inside being more negative relative to the outside. For example: the TMPs of squid neurons and $\mathrm{RBC}$ are found to be -60 to $-70 \mathrm{mV}$ and -5 to $-15 \mathrm{mV}$ respectively. These values do not correspond well with the respective total free ion concentration differentials (in and out) for the two different cells.

Table 1: Ionic concentrations in neurons/erythrocytes and their immediate environments

\begin{tabular}{l|ccc|cc|c}
\hline \multirow{2}{*}{ Charge source } & \multicolumn{3}{|c|}{ Major Cations $(\mathbf{m M})$} & \multicolumn{2}{c|}{ Major Anions $(\mathbf{m M})$} & Major Cations - Major Anions \\
\cline { 2 - 7 } & $\mathrm{K}^{+}$ & $\mathrm{Na}^{+}$ & $\mathrm{Ca}^{2+/} \mathrm{Mg}^{2+}$ & $\mathrm{Cl}^{-}$ & $\mathrm{HCO}_{3}^{-}$ & \\
\hline Axoplasm & $400-335$ & $50-52$ & $\sim 1$ & $95-135$ & $\sim 1.6$ & $(425-117)=308$ \\
Squid Blood & 20 & 440 & $\sim 10$ & 560 & $\sim 3.3$ & $(470-563)=-93$ \\
Seawater/SC & $10 / 220$ & $445 / 312$ & $n a$ & $580 / 167$ & $n a$ & $n a$ \\
\hline Erythroplasm & 139 & $12-11$ & $\sim 1.3$ & 4 & $\sim 12$ & $(153-16)=137$ \\
Serum & $4.0-3.8$ & 145 & $\sim 3.3$ & 116 & $\sim 29$ & $(152-144)=8$ \\
\hline
\end{tabular}

Consensus data chiefly compiled from earlier cited textbooks, Milo \& Phillips, 2015; Villegas et al., 1965; Reza et al., 2019, etc. The values of protein charges, divalent cations and bicarbonate anions are approximated averages derived from a survey of multiple sources. In the initial state, the concentration of protons and hydroxide ions are not deemed to be of high importance, as they are in usually present at $\mathrm{nM}$ to $\mu \mathrm{M}$ ranges within physiological regimes. SC and Prot stand for Schwann cell and proteins respectively. Since the various ions have been determined by several groups and the values are fairly consistent, errors in estimation could arise primarily from the protein charges (which are inconsequential in the flux treatment, as they are immobile with respect to the pores). In the RBC-serum system, it can be seen that the net charges are more or less equal.

Further, a survey of literature would show the discerning reader that the resting TMP is not directly correlated to the in/out distribution of the major anions for diverse cells. Though the 
resting TMP is almost always negative, the ions' and electrostatic charge distribution varies across systems. Further, Brinley's exhaustive analysis of in/out differences of major ions $\left(\mathrm{Na}^{+}\right.$, $\mathrm{K}^{+}$, and $\mathrm{Cl}^{-}$) in resting phase and during stimulation shows that such ionic concentrations alone cannot statistically explain the functioning of various types of animal neurons/cells (Brinley, 1965). Macroscopic phases are generally considered to be charge-neutralized with respect to ionic components. That is- the total number of positive and negative ionic charges are roughly equal in a given phase (say, cytoplasm or blood). Therefore, the prevailing considerations deem the cellular components to be in a 'vitally determined state', as opposed to a 'thermodynamically and electromagnetically probable' state.

(v) Even dead cells or artificially made 'membrane or protein blobs' that do not have selective ion channels or pumps may have TMP (Ling, 1973, 1992). TMP generation and action potentiallike phenomena at the non-biological solution interface have been continuously reported for more than a half century in the physical chemistry field. In this context, Sidney Fox's works reported that proteinoid microspheres (globular mass of polymeric chains derived by heating a mixture of amino acids) generate 'action potential-like electrical signature' spontaneously (Ishima, 1981; Przybylski et al., 1982; Przybylski \& Fox, 1984; Przybylski, 1985; Vaughan, 1987; Haefner, 1992). The striking similarities are easily recognizable, as shown in Figure 3.

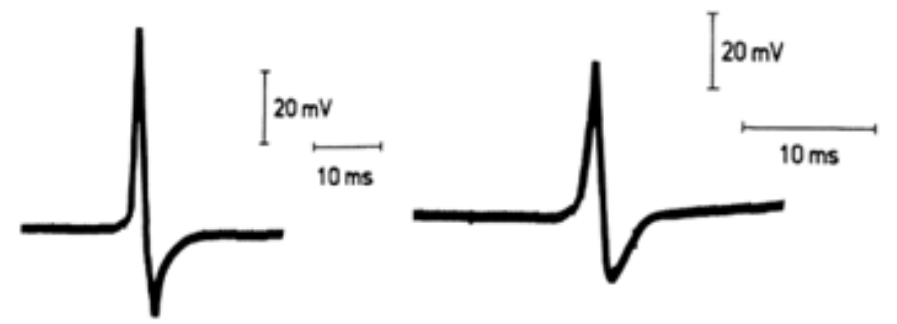

Living cell

Synthetic microsphere

Figure 3: Traces of potential in living cell and non-living synthetic proteinoid microsphere. [From "Evolution of Information Processing Systems", K. Haefner (Ed.), Springer, Berlin 1992.]

The proteinoid microsphere is not a living system and it does not have any membrane channels and pumps, and cannot actively do chemical work on its own. This salient observation makes the 'in vogue' theory of TMP and the conduction of action potential impulse seem superfluous. 
(vi) One of the authors of this paper developed a Goldman-Hodgkin-Katz (GHK) type equation (Hille, 2001) for trans-membrane/action potential from the conceptual foundations of the Ling theory and this was supported with adequate experimental evidence (Tamagawa, 2018; Tamagawa and Ikeda, 2018). Therefore, mere mathematical modeling of a potential trace does not validate the underpinning mechanistic assumptions of the GHK model, and the theoretical foundations must also be mechanistically valid (i.e. the terms in the equation must have realistic bearing with respect to in situ conditions).

(vii) Hitherto available theories of TMP/action potential required trans-membrane ion movements or ion-adsorption. Very importantly, trans-phase electron transfers (as mediated by oxygen-centered radicals), a salient outcome of metabolism/physiology, have been slighted. Oxygen-centered diffusible radicals have been long implicated as a probable causative that could affect TMP (Scott \& Rabito, 1988). This idea has been confirmed by metabolic explorations in mitochondrial physiology, wherein it was found that TMP is directly correlated to ATP synthesis and diffusible reactive oxygen species (DROS) within milieu (Nicholls, 2004). Recent research has shown that oxygen-centered radicals' formation is facile in a low-proton concentration aqueous mixture of salts and peroxide (Stoin et al., 2013). However, it must be disclaimed that since TMP is not just observed in living systems (but also dead cells and in reductionist systems), DROS-centric metabolism or life processes may not be the only cause for TMP! In this regard, murburn concept (Manoj, 2018b) is a new theory electron transfers, which involve simple equilibriums of molecules, unbound ions and radicals in milieu.

The compiled data from Table 1 for erythrocytes is expanded below in Table 2, to search for correlations between the concentrations of ions (if any!). The distribution ratio of the four cations $\left(\mathrm{K}^{+}, \mathrm{Na}^{+}, \mathrm{Ca}^{2+} \& \mathrm{Mg}^{2+}\right)$ inside the $\mathrm{RBC}$ was found to be $73: 6.3: 0.003: 1$, respectively. When compared with respect to a single ion of calcium, $\sim 2.4 \times 10^{4} \mathrm{~K}^{+}$and $2.1 \times 10^{3} \mathrm{Na}^{+}$ions are found in erythrocytes! A simple analysis of the data did not give any tangible correlation of the monovalent or divalent ions, with respect to their concentrations inside or outside. This finding does not align well with the operation of biologically deterministic membrane-pumps, which are supposed to work with specific ratios (Voet \& Voet, 2011). Further, since RBC lack 
mitochondria, substrate-level phosphorylations (as provided by say, glycolysis) cannot furnish the ATP that would be required for maintaining this highly cost-ineffective exercise. Therefore, the active ion-pumping theory is questionable.

Table 2: Distribution profiles of the major cations and anions in human erythrocytes

\begin{tabular}{ccccccccc}
\hline Item & $\begin{array}{c}\mathrm{K}(+) \\
\text { (a) }\end{array}$ & $\begin{array}{c}\mathbf{N a}(+) \\
\text { (b) }\end{array}$ & $\begin{array}{c}\mathbf{C a}(++) \\
\text { (a) }\end{array}$ & $\begin{array}{c}\mathbf{M g}(++) \\
\text { (b) }\end{array}$ & $\begin{array}{c}\mathbf{C l}(-) \\
\text { (a) }\end{array}$ & $\begin{array}{c}\mathbf{H C O}_{\mathbf{3}}(-) \\
\text { (b) }\end{array}$ & Pi (?) & Protein (?) $^{\#}$ \\
\hline RBC (in) & $139 \mathrm{mM}$ & $12 \mathrm{mM}$ & $5.7 \mu \mathrm{M}$ & $1.9 \mathrm{mM}$ & $4 \mathrm{mM}$ & $\sim 12 \mathrm{mM}$ & $\sim 18 \mathrm{mM}$ & $\sim 123 \mathrm{mM}$ \\
Serum (out) & $4 \mathrm{mM}$ & $145 \mathrm{mM}$ & $1.8 \mathrm{mM}$ & $0.8 \mathrm{mM}$ & $116 \mathrm{mM}$ & $\sim 29 \mathrm{mM}$ & $\sim 1.2 \mathrm{mM}$ & $\sim 8 \mathrm{mM}$ \\
In/Out & 35 & 0.08 & 0.003 & 2.4 & 0.034 & 0.414 & 15 & 15.3 \\
In (a/b)* & 12 & $\mathrm{NA}$ & 0.003 & $\mathrm{NA}$ & 0.333 & $\mathrm{NA}$ & $\mathrm{NA}$ & $\mathrm{NA}$ \\
Out (b/a)* & $\mathrm{NA}$ & 36 & $\mathrm{NA}$ & 0.44 & $\mathrm{NA}$ & 0.25 & $\mathrm{NA}$ & $\mathrm{NA}$ \\
\hline
\end{tabular}

(NA: not applicable or not available); (*a/b or b/a values are taken for the respective columns of monovalent cations, divalent cations and monovalent anions only); (extrapolated from law of electroneutrality)

A compilation of the abundance of the ions on earth, weight, solubility of the respective chloride (an abundant anion in nature and in physiological realms) dimensions, dimensions, and some thermodynamic properties (Bazhin, 2020) is presented in Table 3. It can be envisaged that the relative abundance/solubility of the ions could determine their bioavailability. Further, ionic mass and charge would determine work done in moving ions across membranes. None of the first three parameters were found to directly/tangibly correlate to the physiological distribution of the cations, when considering the full spectrum (of $\mathrm{K}-\mathrm{Na}-\mathrm{Ca}-\mathrm{Mg}$ ). Ionic dimensions would determine filtration/pumping (through membrane proteins) and also affect the hydration shell sizes. Therefore, it is a very important criterion for both the classical membrane theorists (Voet \& Voet, 2011) and the alternative schools of thought (like association-induction hypothesis, as seen in Gilbert Ling's works at www.gilbertling.org). This is the reason why data are presented in the order of decreasing ionic radius in Tables $2 \& 3$. Yet again, it is difficult for us to envisage that membrane pores could kinetically/viably enable a selective differentiation of di- or monovalent ions of dimensions ranging $\sim 1.7 \AA\left(\mathrm{Mg}^{2+}\right)$ to $\sim 2.3 \AA\left(\mathrm{Ca}^{2+}\right.$ or $\left.\mathrm{Na}^{+}\right)$to $\sim 3.0 \AA\left(\mathrm{K}^{+}\right)$. That is: while the smaller species can be easily selected, the larger species would invariably/statistically bring along the smaller one, if size/charge were the deterministic criteria. This predicament would necessitate directional pumps/channels for each of the species, and such processes would not be efficient. Table 3 shows that ionic radius is inversely correlated to Gibbs free energy of 
formation or $\Delta_{\mathrm{f}} G^{\prime \mathrm{o}}$ aq $\left(\right.$ i.e. as ionic radius decreases, $\Delta_{\mathrm{f}} G^{\prime \mathrm{o}}$ aq increases) and directly correlated to Gibbs solvation energy or G.S.E. (i.e. as ionic radius decreases, G.S.E. also decreases). While the differences in thermodynamic properties are significant, they are unidirectional with respect to ionic size. The hydration radius argument would predict the cellular availability in along the order $\mathrm{K}>\mathrm{Na}>\mathrm{Ca}>\mathrm{Mg}$ over the spectrum or $\mathrm{K}>\mathrm{Na}$ for monovalent ions and $\mathrm{Ca}>\mathrm{Mg}$ for divalent ions. The actual physiological order is $\mathrm{K}>\mathrm{Na}>\mathrm{Mg}>\mathrm{Ca}$. That is, while AIH's prediction is correct for the monovalent ions, the case of divalent ions is inaccurate! Therefore, "ion-water reorganization mediated by proteins+ATP" does not appear to be the sole/direct factor in determining the outcomes and AIH alone cannot justify the observed physiological outcome in Table 2. Clearly, none of the parameters in Table 3 provide a direct or simple/tangible rationale for the physiological distribution of cations.

Table 3: Fundamental physical attributes of the four cations explored herein

\begin{tabular}{|c|c|c|c|c|c|c|}
\hline S. No. & Criteria & $K(+)$ & $\mathrm{Na}(+)$ & $\mathrm{Ca} \mathrm{(++)}$ & $\mathrm{Mg}(++)$ & Average \pm st.dev. \\
\hline 1 & Abundance & $2.09 \%$ & $2.36 \%$ & $4.15 \%$ & $2.33 \%$ & $2.73 \pm 1 \%$ \\
\hline 2 & Solubility $(\mathrm{Cr})$ & $4.6 \mathrm{M}$ & $6.15 \mathrm{M}$ & $6.71 \mathrm{M}$ & $5.74 \mathrm{M}$ & $5.8 \pm 0.9 \mathrm{M}$ \\
\hline 3 & Atomic mass & $39 \mathrm{~g}$ & $23 \mathrm{~g}$ & $40 \mathrm{~g}$ & $24.3 \mathrm{~g}$ & $31.6 \pm 9 \mathrm{~g}$ \\
\hline 4 & Ionic radius & $152 \mathrm{pm}$ & $116 \mathrm{pm}$ & $114 \mathrm{pm}$ & $86 \mathrm{pm}$ & $117 \pm 27 \mathrm{pm}$ \\
\hline 5 & $\Delta_{\mathrm{f}} G^{\prime \mathrm{o}} \mathrm{aq}$ & $129 \mathrm{~kJ} / \mathrm{mol}$ & $151 \mathrm{~kJ} / \mathrm{mol}$ & $271 \mathrm{~kJ} / \mathrm{mol}$ & $370 \mathrm{~kJ} / \mathrm{mol}$ & $230 \pm 112 \mathrm{~kJ} / \mathrm{mol}$ \\
\hline 6 & G.S.E. & $-352 \mathrm{~kJ} / \mathrm{mol}$ & $-424 \mathrm{~kJ} / \mathrm{mol}$ & $-1608 \mathrm{~kJ} / \mathrm{mol}$ & $-1931 \mathrm{~kJ} / \mathrm{mol}$ & $-1079 \pm 809 \mathrm{~kJ} / \mathrm{mol}$ \\
\hline
\end{tabular}

\section{Transduction of the external chemico-physical stimuli to a localized internal chemo-} electrical signal; the intertwining of TMP and homeostasis: All cellular works can only be commissioned by electromagnetic forces. This means that ultimately, cellular systems are simple chemical arrays that need to use their structures to generate and decipher a chemo-electrical signal. In this regard, sensory stimuli could be broadly classified into- chemical (pH, ions/molecules, etc.), thermal (temperature differences), mechanical (pressure, sound, stress/strain, proprioception, etc.), propagating radiations (UV, infrared, various visible wavelengths, etc.) and other types of electro-magnetic fields. Some of these sensory functions may overlap, for example- heat sensing can be done via infrared reception and electric field sensing can be based on chemical/ionic fluxes. However diverse the 'sensation' received and however specialized the reception/effecting module, at least a simple electrochemical event must 
be relayed via the neuronal networks. This could be a combination of the pseudo-electrical impulse along the axon and chemicals released at synapses, finally giving a signal that the animal's discretionary control center (a ganglion or brain) can decipher. Currently, biologists predominantly use "protein conformation change" as the explanation for most sensory stimuli's transduction processes. For example- when light falls on rhodopsin, it is supposed to change the configuration of retinal, which in turn, is envisaged to change the conformation of the bound protein, leading to a trans-membrane proton-pump mechanism. Such suppositions were shown to be inaccurate in recent times (Manoj, 2018a,b; Manoj et al., 2019a-c, Manoj et al., 2020a-d, Manoj \& Jacob, 2020; Manoj \& Manekkathodi, 2021). So, how does the purely physical signal get transduced and relayed as a chemo-electrical signal (action potential) that originates at a particular locus, and gets directionally conveyed to reach yet another locus? Why doesn't the 'soliton or ionic ripple' die away or lose steam along the way? The biological membrane can hardly be seen as a hard-wired electrical system. One of us has already demonstrated (quite contrary to prevailing/acclaimed suppositions) that deterministic "electron transport chains" cannot exist/function at chloroplast or mitochondrial or endoplasmic reticulum membrane interfaces (Manoj, 2018a; Manoj et al., 2019a-c; Manoj et al., 2020a-d). This emergent scenario could impact other physiological processes/systems also. In this connection, one of us proposed a new model for the photoreception process in human retina (Manoj \& Jacob, 2020). This proposal was in line with the newly advocated photo-energy transduction process for light's interaction with various pigments in the chloroplasts (Manoj \& Manekkathodi, 2021). Clearly, such recent developments are beyond the purviews of classical and AIH explanations, and invoke murburn concept's role in homeostasis and electrophysiology. Living cells/tissues and milieus are predominantly comprised of molecules and ions. However, there is a small but significant amount of radicals that are unavoidable, which could play significant roles in life processes. Recently, several metabolic and physiological outcomes were demonstrated to proceed to through oxygen-centered radicals and ionic intermediates (Manoj's group's works cited earlier). The source of TMP in mitochondria was recently attributed to a steady-state deficiency of positive charges within (and not owing to the pumping out of positively charged protons!), owing to metabolic processes within the organelle. Also, it was shown that the homeostatic process and TMP are intricately connected by the colligative properties' dynamics that result 
from metabolic activities (Manoj et al., 2019b-c). Such findings bring a totally new perspective to the discussion, and the murburn interfacial phenomenon could potentially unify the divergent perspectives of membrane and bulk phase theory.

\section{The problem of changing cell surface area versus volume, and the problem of water flux:}

The membrane theory fails to explain intake of excess water into the cell, with the concomitant increase in volume and surface area. The increase in volume and surface area beyond a critical point would introduce gaps or holes, thereby compromising the integrity of the barrier or boundary (and this should 'kill' the cell). The fact that such changes of significant magnitudes are accommodated by living cells is an intangible problem for the membrane theory. Here, bulkphase or sol-gel centered theory appear to be more appealing. Also, Jacques Loeb's works (in the earlier part of $20^{\text {th }}$ century) showed that gel based systems, without a defined membrane-like periphery, could give rise to potential differences. Other champions of such views included Dimitri Nasonov of the past and Gerry Pollack, Vladimir Matveev, etc. of recent times and their findings/voices are important in the context of this discussion. Water and ionic flux could be aided by membrane porins and ion channels, and this is a context that is not addressed by AIH. For example- uncoupling proteins of brown adipose tissue are also known as acyl carrier proteins. Their trans-membrane pore regions are filled with positively charged residues like lysine and arginine (Manoj et al., 2018). In routine physiology, water formation and consumption is a highly dynamic process (Frenkel-Pinter et al., 2021) and it is not clear how the cells/organelles could homeostasize without the intervention of supra-molecular governance. In this regard, one of us proposed a murburn colligative mechanism for the fundamental metabolic routines of aerobic respiration (Manoj et al., 2019b-c), oxygenic photosynthesis (Manoj et al., 2020b; Manoj \& Manekkathodi, 2021), and xenobiotic metabolism (Parashar \& Manoj, 2021). This development necessitates a revisit to the explanations.

E. The mechanism of gating and the question of cause versus consequence: We find it counter-intuitive and thermodynamically untenable that ionic differentials across membranes are deemed to be the cause of TMP and they are also used to drive the very same ions across the very same membrane. One of us has effectively dislodged this perspective with respect to proton 
pumps in mitochondrial physiology (Manoj, 2018a; Manoj et al., 2018; Manoj et al., 2019a,b). The voltage-gated opening and closing of membrane protein pores is a crucial component of the explanation for the propagation of neuronal impulse. It is not known how voltage can change/affect the protein pore's aperture. In this regard, the bigger issue is that the acclaimed belief system advocates both premises: TMP (voltage) is governed by the opening of membrane pores and the membrane pores' opening is also governed by voltage. This imbroglio leads to an illogical "catch 22 or zugzwang". One of us had shown and argued in mitochondrial physiology that TMP results as a consequence of metabolic activities (electron transfers) within, and is not the primary driving force for the transport of ions (Manoj et al., 2019a-c). Thus, the attribution of "horse and cart" (the driver and the driven) were revamped. It is quite possible that similar confusions prevail in this physiological research realm too. Also, the acclaimed model allows the untenable simultaneous bi-directional flow of very similar cations across a polarized neuronal membrane! Such a flux seems to be sustainable only in a vitally deterministic hypothesis/model and cannot be acceptable with respect to fundamental concepts of electrochemistry, as there would be little thermodynamic rationale for such process (Manoj et al., 2020b,c).

F. The cellular response formats: The ability to respond to a stimulus relies on how a cell is structured/composed and senses the external change. The physiological process (and therefore the outcome) could be via four modalities- "an all or none, digital type" OR "threshold-driven operation" OR “a discretized maverick fashion" OR "an incrementally tweak-able or graded, analog type modality". Both the classical and AIH explanations cannot address such types of processes/outcomes at the same time (and neither can genetic regulations bring about such maverick outcomes). This is because simple reactions or ligand-receptor or enzyme-substrate based interactions or recognition/quantitation strategies give only limited outcome profiles, as shown in Figure 4. Unidirectional increasing or decreasing linear (e.g. simple first order reactions) or hyperbolic (e.g. Michaelis-Menten asymptotes) and sigmoidal (e.g. allosteric activation or inhibition of enzymes) profiles are shown in panels A and B, respectively. In panel $\mathrm{C}$, bidirectional bell-shaped curve (e.g. activity profile of an enzyme with respect to $\mathrm{pH}$ ) or a practically zero-order response (e.g. some radical reactions) with respect to a given reactant are depicted. Panel D shows erstwhile inexplicable multi-phasic lines/curves, with discrete optimal 
values of concentrations. One of us has recently elaborated that such hormetic or idiosyncratic responses (multi-phasic lines/curves) could result from 'murburn' electron-transfers at phospholipid interfaces (Parashar et al., 2018).
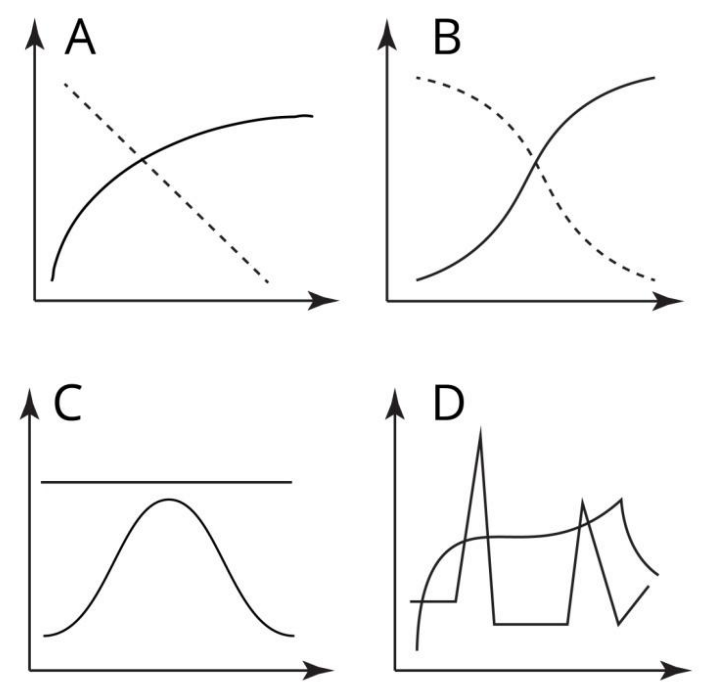

Figure 4: Examples of physiological dose responses (The vertical arrows depict activity and the horizontal arrows show concentrations, in linear or log scales. Dashed lines or curves depict lowering activity profiles with increasing concentrations of the reactant/substrate/ligand.)

\section{G. The enigma of 'saltatory progression' in myelin-sheathed neurons: While an average} animal axon core's diameter is variable, dimensions of $\sim 0.5$ micron or more (even up to several hundreds of microns, as seen in giant axons of squids) are common and its external myelin wrap (if present) could easily be $\sim 0.3$ micron thick at any side, except at the nodes of Ranvier (Graf von Keyserlingk \& Schramm, 1984). The nodes of Ranvier are usually 1-2 micron gaps between the continuously sheathed axon of various lengths, which range from a few tens of microns to several hundreds of microns (Arancibia-Carcamo et al., 2017). It is known that cells with myelinated sheaths conduct the neuronal impulse much faster $(\sim 250 \mathrm{~m} / \mathrm{s})$ than nonmyelinated cells $(\sim 25 \mathrm{~m} / \mathrm{s})$. The GHK's 'cable theory' reasoning for the above observation is that insulation afforded by myelin-wrapping is supposed to decrease capacitance and increase resistance in the myelinated region, causing the 'jumping of potential from node to node'. This explanation would be antithetical to the fundamental suppositions of the GHK model itself, which deems capacitance and conductance (resulting in a deterministic alternation of positive and negative charges near the peripheries of nerve fiber) along the nerve membrane as the 
primary reasons for neuronal impulse propagation. Also, given the contemporary awareness of dimensions of the fiber-sheath-nodes and distributions of proteins and ions therein, the GHK model fails to explain how the action potential 'jumps' distances of several hundred microns without the channels and ions necessary for its conduction. The structure-function correlations in neuronal cells are not fully explained by the GHK model, which was developed much before more precise structural awareness on neurons were unraveled.

H. Miscellaneous unresolved issues: We find that the structural rationale provided till date for selectivity in pumping/channeling of ions through membrane proteins is not convincing enough. Further, it remains to be investigated if the binding of the 'cardinal ligand' ATP induces adequate conformational changes that enable selective binding of ions (for e.g. preferential binding of $\mathrm{K}^{+}$over $\mathrm{Na}^{+}$) within the bulk phase (in the AIH purview). In this regard, Ling's assertion that such binding of ATP to proteins rearranges the water-lattice around them needs to be amply supported by spectroscopic and experimental data. Most importantly, we find the existence of selective molecular pumps at the membrane interface a major problem with the concept of molecular evolution. That is: the current perceptions pre-require an "irreducibly complex" ionic pumping mechanism's existence for the origin and sustenance of life. The recent negation of proton-pumps in mitochondria and chloroplasts (Manoj's group's works cited) and demonstration of radicals' involvement necessitate theoretical frameworks that extend beyond membrane theory and AIH perspectives. The global synchronization/timing of pore openings for conduction of the neuronal impulse, larger action potential for smaller-bore neuronal fibers, propagation/collation of the action potential along branching fibers (noted in physiological functioning neurons), etc. are some of the other specific question which remain unresolved.

\section{Predictive exploration based on murburn concept}

Cells can be deemed to work as redox machines, and cellular redox processes are based on electron transfers and equilibriums amongst its component molecules and ions. Murburn concept is an interactive equilibrium of molecules, ions and spontaneously formed radicals in cell metabolism/physiology (Manoj, 2018b; Manoj, 2020b). Till date, it has presented explanations 
for diverse fundamental aspects of life: moiety and electron transfers mediated by heme-/flavinenzymes (Manoj, 2006; Manoj \& Hager, 2008; Manoj et al., 2010; Andrew et al., 2012; Parashar et al., 2014; Manoj et al., 2016a-b), aerobic respiration (Manoj et al., 2019a-b; Manoj et al., 2020a), oxygenic photosynthesis (Manoj et al., 2020b,c; Manoj \& Manekkathodi, 2021), xenobiotic metabolism (Manoj et al., 2016c; Parashar \& Manoj, 2021), idiosyncratic/hormetic dose responses (Parashar et al., 2018), homeostasis/trans-membrane potential/thermogenesis (Manoj et al., 2018; Manoj \& Bazhin, 2019), signal transduction in vision (Manoj \& Jacob, 2020d), explanations for hemoglobin's role as an ATP-synthase in erythrocytes (Manoj et al., 2021), etc. Figure 5 shows a schematic of the interactive equilibriums of murburn concept.

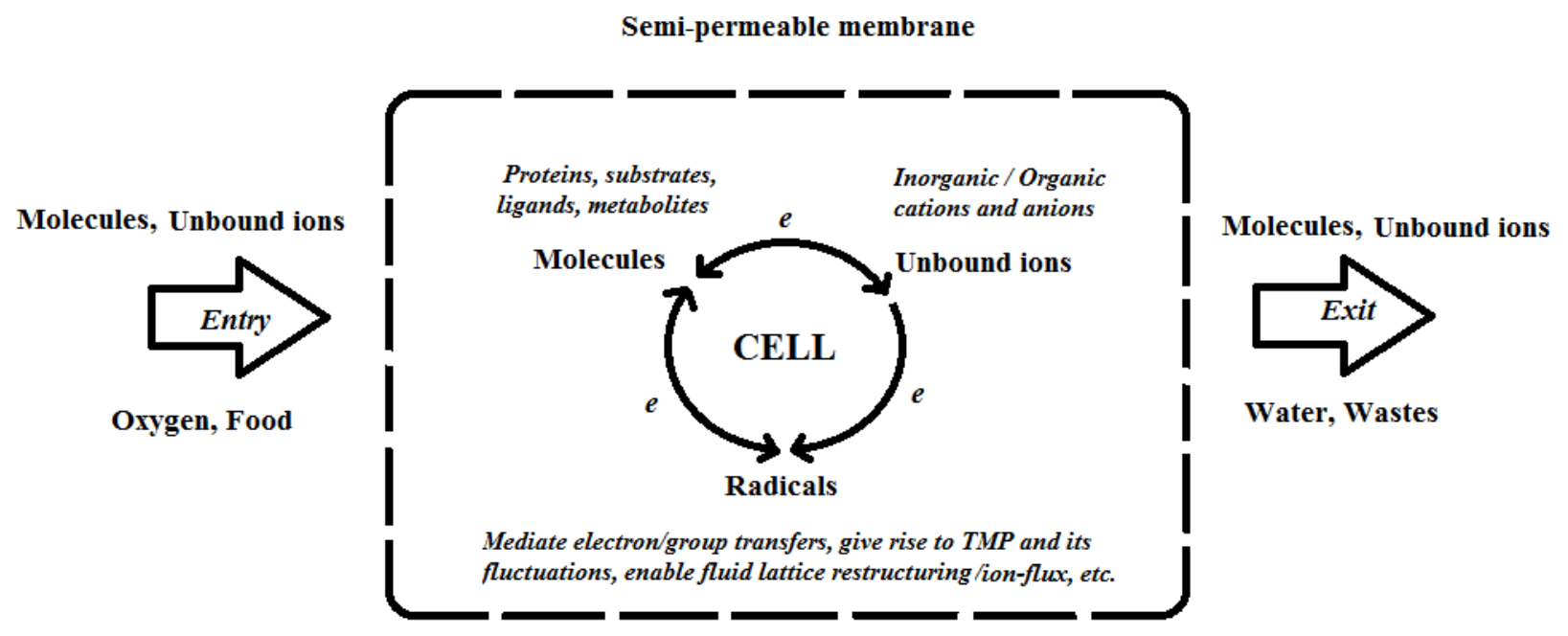

Figure 5: The murburn purview of cellular metabolism and homeostasis

Since cellular bioenergetic routines are fundamentally based in murburn principles, it is forthright to postulate that cellular composition would be dictated by the catalysts/intermediates/products of metabolism. With relevance to context, those cations that are preferred by the constituent proteins (which are the stable and relatively non-changing components/adsorbents in cells) and those anions that are intermediates/products of respiration (those species that are in high turnovers within the cell) would have the propensity to dictate the outcomes. Based upon such an intuitive thought-line, the solubility profiles of four anions of respiratory relevance (for which we could access data from literature: carbonate, acetate, bicarbonate and phosphate) were probed from the solubility table of Wikipedia (as extracted 
from CRC Handbook of Chemistry \& Physics). Table 4 presents the summary of this data, which shows that two anions gave a solubility profile of the same relative order as found in RBC for all the four cations, and two more anions gave good correlations with at least three of the cations. Unlike the solubility data for chloride, these anions show a high degree of selectivity/variance for the four cations. Clearly, the solubility of these salts must contribute to achieving the physiological outcomes. Carbonate/bicarbonate and acetate are directly the output of carbon metabolism (aerobic respiration) and phosphate is also involved in bioenergetic turnovers. Particularly, it can be seen that phosphate is very selective to potassium, as opposed to calcium; thereby explaining the oddity discussed for Table 2. Significant concentrations of carbonatebicarbonate and phosphate ions are found within cells, in the ranges of $10^{1} \mathrm{mM}$. In fact, further search showed that organic phosphates (e.g. ATP/UDP, hexose phosphate, pentose phosphate, etc.) and organic acids (like glutamate, aspartate, citrate, malate, succinate, acetate, etc.) compose a whopping $\sim 68 \%$, and proteins make up $\sim 18 \%$; a grand total of $\sim 86 \%$ the cellular anionic charges (Bennet et al., 2009; Anderson, 2013; Milo \& Philips, 2015) in E. coli! So, the skewed cationic distribution primarily results as a direct outcome of the powering murburn equilibriums/fluxes (Manoj, 2018; Manoj, 2020) within metabolism/physiology. Contrary to earlier perceptions, one-electron processes could be facile in cells and this would be a more plausible explanation for several phenomena than a merely adsorption-based explanation.

Table 4: Absolute and relative solubility ratios of some salts in water

\begin{tabular}{cccccc}
\hline S. No. & Anion & $\mathbf{K ~ ( + )}$ & $\mathbf{N a ~ ( + )}$ & $\mathbf{C a ~ ( + + ) ~}$ & $\mathbf{M g}(++)$ \\
\hline 1 & Carbonate & $8.04 \mathrm{M}$ & $2.02 \mathrm{M}$ & $70 \mu \mathrm{M}$ & $4.6 \mathrm{mM}$ \\
& (Ratio) & $\mathbf{1 . 7 \times 1 0 ^ { 3 }}$ & $\mathbf{4 . 4 \times 1 0 ^ { 2 }}$ & $\mathbf{1 . 5 \times 1 0 ^ { - 1 }}$ & $\mathbf{1}$ \\
2 & Acetate & $26 \mathrm{M}$ & $5.7 \mathrm{M}$ & $2.2 \mathrm{M}$ & $3.75 \mathrm{M}$ \\
& (Ratio) & $\mathbf{6 . 9}$ & $\mathbf{1 . 5}$ & $\mathbf{0 . 6}$ & $\mathbf{1}$ \\
3 & Bicarbonate & $2.24 \mathrm{M}$ & $1.14 \mathrm{M}$ & $1.02 \mathrm{M}$ & $4.2 \mathrm{mM}$ \\
& (Ratio) & $\mathbf{5 . 3 \times 1 0 ^ { 2 }}$ & $\mathbf{2 . 7 \times 1 0 ^ { 2 }}$ & $2.4 \times 10^{2}$ & $\mathbf{1}$ \\
4 & Phosphate & $4.35 \mathrm{M}$ & $0.74 \mathrm{M}$ & $64.5 \mu \mathrm{M}$ & $1 \mu \mathrm{M}$ \\
& (Ratio) & $\mathbf{6 . 7 \times 1 0 ^ { 4 }}$ & $\mathbf{1 . 1 \times 1 0 ^ { 4 }}$ & $\mathbf{1}$ & $1.6 \times 10^{-2}$ \\
\hline
\end{tabular}

Hence, the classical Debye-Huckel equation for solubility can be applied in this case.

$\log (\gamma \pm)=-\left[1.824 \times 10^{6} /(\epsilon T)^{3 / 2}\right]\left|z_{+} z_{-}\right|(\sqrt{ } I)$

$I=$ ionic Strength

$z_{+}$or $z_{-}=$catonic or anionic charge of the electrolyte for $\gamma \pm$

$\gamma=$ mean ionic activity coefficient 
$T=$ temperature of solution

$\epsilon=$ relative dielectric constant for the solution

At $298 \mathrm{~K}$, the equation for solubility of the ion becomes

$\log (S / S o)=-0.509\left|z_{+} z_{-}\right|(\sqrt{ } I)-K^{\prime} I$

$K^{\prime}=$ the is a constant dependent on the size of the solute and the ions present, $S=$ the solubility and $S_{0}$ is the solubility in pure solvent.

The total concentration of major cations $\left(\mathrm{K}^{+}\right.$and $\left.\mathrm{Na}^{+}\right)$turns out to be $\sim 150 \mathrm{mM}$ (both in and out of $\mathrm{RBC}$ ) and the minor cations $\left(\mathrm{Ca}^{2+}\right.$ and $\left.\mathrm{Mg}^{2+}\right)$ add up to $2 \%$ of the above value (Table 2). The law of electro-neutrality of phases dictates a similar concentration range of the total anionic charges in each phase. From an ab initio perspective, the major difference between erythroplasm and serum is the concentration of proteins, the biggest protagonist in cytoplasm. We also know that proteins form a significant source of negative charges in the cell. It is long known that Hofmeister series (Okur et al., 2017) indicates that the experimentally observed cation binding/adsorption of most cytoplasmic proteins is approximated in the order $\mathrm{K}^{+}>\mathrm{Na}^{+}>\mathrm{Mg}^{++}>$ $\mathrm{Ca}^{++}$. Therefore, both binding affinities of bulk-phase proteins and the ions involved in metabolic turnovers can come together (as an integral function) to achieve the physiological distribution of ions in cells. This is a simple and parsimonious deduction, and it is also supported by the consideration that highly sophisticated membrane-embedded ion-pumps would not be needed for the evolution of life in the primordial stages. Further, attainment of the physiological distribution of ions would not require any intelligent control via membrane-proteins' concentrations/functions or through exorbitant expenditure of ATP. In short, a good analogy comes to mind, to effectively capture the essence of the overall process. The number or type of people that reside in a locale (say, a county or country) is decided by screening at the borders (membrane theory components) and by the discretion of citizens (adsorption theory components). The elements that murburn theory enlists include the dynamics and mechanistic of the overall process- why some borders can't be policed, why some residents do not like drifters, etc. The findings herein do not negate the existence of membrane-embedded ion-channels but call for a revisit of the mechanisms for cellular homeostasis and trans-membrane potential (TMP). For solvation, the solvent-lattice must be broken first to introduce a cavity, into which ions can be placed; this is both enthalpically and entropically disfavored. In this regard, for explaining the ionic distribution 'in and out' of the physiologically ordered milieu, the migration and solvation of 'anion+cation' couplet appears to 
be aided by discretized murburn equilibriums, distribution of respiratory molecules, solubilized proteins, membrane channels and semi-permeable membranes. The preliminary aspects of our predictions can be easily tested with a bi-compartmental system (separated by a semi-permeable membrane) housing a mixture of chloride salts of $\mathrm{K} / \mathrm{Na} / \mathrm{Mg} / \mathrm{Ca}$ and introducing various organic phosphates, carbonates, acetates, etc. into one of the compartment.

\section{Conclusions: We need to think of integrating the available options into a new theory!}

Through several distinct critical queries/points listed above, we have demonstrated that some aspects of the acclaimed perspectives of modern physiology of homeostasis and trans-membrane potential overlook the laws of mass action and conservation of energy, and do not agree with well-substantiated observations and evolutionary principles. We have demonstrated that some aspects of the acclaimed/marginalized perspectives of modern physiology fall short at comprehensively explaining diverse aspects of electrophysiology. The membrane theory surely appeals with well-characterized proteins, but is 'irreducibly complex' at its core and can no more claim monopoly for explaining cell physiology. Although simple, the bulk phase approach has several aspects unqualified yet and cannot possibly explain some metabolic complexities of life processes. Both membrane theory and AIH are purely ionic and physical purviews, with little scope for explaining one-electron transfer processes that are crucial to life. The new player of murburn concept (electron transfers in bulk phase or at phospholipid interfaces leading to micro/macro-scopic changes) has succeeded concepts like 'proton-pumps'. Contrary to the misplaced perception of membrane theory, murburn concept has demonstrated that TMP is not the driver of metabolic activities, but is more an outcome of the same. It has also shown that TMP and homeostasis are dynamically and intricately related. The murburn explanation for fundamental metabolic/physiological processes (like aerobic respiration, oxygenic photosynthesis, xenobiotic metabolism, thermogenesis, etc.) and signal transductions at phospholipid interface (as exemplified by photoreception in vision) is well-grounded in thermodynamics and kinetics. Therefore, the minimalistic and evolutionarily facile murburn purview could potentially bridge the lacunae presented by the membrane theory and AIH bulk-phase; and link diverse metabolic/adsorption phenomena with membrane-related electrophysiological processes. 
Henceforth, integration of various aspects of membrane theory (membrane-channels, in particular), bulk-phase approach and murburn concept need to be explored for better explaining metabolic electrophysiological outcomes of TMP and homeostasis. We project that dynamic electron transfers at the interface can also lead to TMP and action potential. It is imperative in the context that a theory is amalgamated (based on the murburn model/hypothesis) on how electron transfers are linked to water-lattice changes and ionic fluxes.

Declarations: The work was powered by Satyamjayatu: The Science \& Ethics Foundation. KMM thanks Vivian David Jacob for drawing Figures 1, $2 \& 4$ and for providing critical inputs/information. The authors have no conflict of interests to declare.

\section{References}

1. Alberts, B., Johnson, A., Lewis, J., Raff, M., Roberts, K., Walter, P. Molecular Biology of the Cell $4^{\text {th }}$ edn. Garland Science (2002).

2. Andersen, O. 'Cellular electrolyte metabolism' in Encyclopedia of Metalloproteins, Springer, pp. 580-587 (2013).

3. Andrew, D. et al. The intriguing enhancement of chloroperoxidase mediated one-electron oxidations by azide, a known active-site ligand. Biochem. Biophys. Res. Commun. 415, 646-649 (2012).

4. Arancibia-Carcamo, L., Ford, M. C., Cossell, L., Ishida, K., Tohyama, K., Atwell, D. Node of Ranvier length as a potential regulator of myelinated axon conduction speed. Elife 6:e23329 (2017).

5. Bazhin, N. M. Standard values of the thermodynamic functions of the formation of ions in an aqueous solution and their change during salvation. J. Phys. Chem. A.124, 11051-11060 (2020).

6. Bennett, B., Kimball, E., Gao, M. et al. Absolute metabolite concentrations and implied enzyme active site occupancy in Escherichia coli. Nat Chem Biol 5, 593-599 (2009)

7. Berg, J. M., Tymoczko, J. L., Stryer, L. Biochemistry $5^{\text {th }}$ edn. W H Freeman (2002).

8. Bockris, J. O’M. \& Khan, S. U. M. Surface Electrochemistry A Molecular Level Approach. Plenum, New York (1993).

9. Brett, C. M. A. \& Brett, A. M. O. Electrochemsitry Principles, Methods and Applications. Oxford University Press, New York (1993).

10. Brinley, F. J. (Jr.). Sodium, potassium and chloride concentration and fluxes in the isolated giant axon of Homarus. J. Neurophysiol. 28:742-772 (1965).

11. Colacicco, G. Electrical potential at an oil/water interface. Nature 207: 936-938 (1965).

12. Edelmann, L. Doubts about the sodium-potassium pump are not permissible in modern bioscience. Cell. Mol. Biol. 16:725-729 (2005).

13. Flasterstein, A. H., Voltage fluctuations of metal-electrolyte interfaces in electrophysiology. Med. \& Biol. Engng., 4: 583-588 (1966a).

14. Flasterstein, A. H., A General analysis of voltage fluctuations of metal-electrolyte interfaces. Med. \& Biol. Engng., 4: 589-594 (1966b).

15. Frenkel-Pinter, M., et al. Water and life: The medium is the message. J. Mol. Evol. (2021). doi: 10.1007/s00239-020-09978-6 
16. Graf von Keyserlingk, D. \& Schramm, U. Diameter of axons and thickness of myelin sheaths of the pyramidal tract fibres in the adult human medullary pyramid. Anat. Anz. 157:97-111 (1984).

17. Haefner, K. (Ed.). Evolution of Information Processing Systems. Springer, Berlin (1992).

18. Hille, B. Ion channels of excitable membranes, 3rd edn. Sinauer Associates, Sunderland, MA (2001).

19. Hofmeister, F. Zur Lehre von der Wirkung der Salze. Arch. Exp. Pathol. Pharmacol. 24, 247-260 (1888).

20. Ishima, Y., Przybylski, A.T. Fox, S. W. Electrical membrane phenomena in spherules from proteinoid and lecithin. Bio. Systems., 13:243-251 (1981).

21. Kish, J. R., Ives, M. B, Rodda, J. R. Corrosion mechanism of nickel in hot, concentrated $\mathrm{H}_{2} \mathrm{SO}_{4} . J$. Electrochem. Soc., 147: 3637-3646 (2000).

22. Kitahara, A. \& Watanabe, A. (eds.) Electrical Phenomena at Interfaces: Fundamentals, Measurements, and Applications (Surfactant Science). Marcel Dekker Inc., New York. (1984)

23. Ling, G. N. A physical theory of the living state: the association-induction hypothesis. (Blaisdell Publishing Company, New York. (1962) [[Also- https://www.gilbertling.org/]]

24. Ling, G. N. How does ouabain control the levels of cell $\mathrm{K}^{+}$and $\mathrm{Na}^{+}$? By interference with a Na pump or by allosteric control of $\mathrm{K}^{+}-\mathrm{Na}^{+}$adsorption on cytoplasmic protein sites? Physiol. Chem. \& Phys., 5:295-311 (1973).

25. Ling, G. N. Revolution in the Physiology of the Living Cell. (Krieger Pub Co, Florida, 1992).

26. Ling, G. N. Debunking the alleged resurrection of the sodium pump hypothesis. Physiol. Chem. Phys. \& Med. NMR 29:123-198 (1997).

27. Manoj, K. M. Chlorinations catalyzed by chloroperoxidase occur via diffusible intermediate(s) and the reaction components play multiple roles in the overall process. Biochim. Biophys. Acta 1764, 1325-1339 (2006).

28. Manoj, K. M. \& Hager, L. P. Chloroperoxidase, a Janus enzyme. Biochemistry 47, 2997-3003 (2008).

29. Manoj, K. M. et al. Cytochrome P450 reductase: a harbinger of diffusible reduced oxygen species. PLoS One 5, e13272 (2010).

30. Manoj, K. M. et al. Electron transfer amongst flavo- and hemo-proteins: diffusible species effect the relay processes, not protein-protein binding. $R S C A d v$. 6, 24121-24129 (2016a).

31. Manoj, K. M. et al. Atypical profiles and modulations of heme-enzymes catalyzed outcomes by low amounts of diverse additives suggest diffusible radicals' obligatory involvement in such redox reactions. Biochimie 125, 91-111 (2016b).

32. Manoj, K. M. et al. Functioning of microsomal cytochrome P450s: murburn concept explains the metabolism of xenobiotics in hepatocytes. Front. Pharmacol. 7, 161 (2016c).

33. Manoj, K. M. Aerobic respiration: criticism of the proton-centric explanation involving rotary ATP synthesis, chemiosmosis principle, proton pumps and electron transport chain. Biochem. Insights 11, 1178626418818442 (2018a).

34. Manoj, K. M. The ubiquitous biochemical logic of murburn concept. Biomed. Rev. 29:89-98 (2018b).

35. Manoj, K. M. et al. Murburn scheme for mitochondrial thermogenesis. Biomed. Rev. 29: 73-82 (2018).

36. Manoj, K. M., Parashar, A., Jacob, V. D., Ramasamy, S. Aerobic respiration: proof of concept for the murburn perspective. J. Biomol. Struct. Dyn. 37, 4524-4556 (2019a).

37. Manoj, K. M. et al. Chemiosmotic and murburn explanations for aerobic respiration: predictive capabilities, structure-function correlations and chemico-physical logic. Arch. Biochem. Biophys. 676, 108128 (2019b).

38. Manoj, K. M., Bazhin, N. M. Murburn precepts of aerobic respiration and homeostasis. OSF Preprints (2019). doi: 10.31219/osf.io/hx4p9

39. Manoj, K. M. Refutation of the cation-centric torsional ATP synthesis model and advocating murburn scheme for mitochondrial oxidative phosphorylation. Biophys. Chem. 257, 106278 (2020a).

40. Manoj, K. M. Murburn concept: A paradigm shift in cellular metabolism and physiology. Biomol. 
Concepts 11, 7-22 (2020b).

41. Manoj, K. M. et al. Acute toxicity of cyanide in aerobic respiration: Theoretical and experimental support for murburn explanation. Biomol. Concepts 11:32-56 (2020a).

42. Manoj, K. M. et al. Murburn precepts for the light reaction of oxygenic photosynthesis and chloroplast homeostasis. OSF Preprints (2020b). doi: 10.31219/osf.io/95brg

43. Manoj, K. M. et al. Is Z-scheme a tenable explanation for the light reaction of oxygenic photosynthesis? OSF Preprints (2020c). doi: 10.31219/osf.io/v6tdf.

44. Manoj, K. M. \& Jacob, V. D. The murburn precepts for photoreception. (In Press) Biomed. Rev. 31 (2020d). doi: 10.31219/osf.io/gmd5t

45. Manoj, K. M. \& Manekkathodi, A. Light's interaction with pigments in chloroplasts: The murburn perspective. J. Photochem. Photobiol. 5, 100015 (2021).

46. Manoj, K. M., et al. Hemoglobin catalyzes ATP-synthesis in human erythrocytes: A murburn model. OSF Preprints (2021). doi: 10.31219/osf.io/ysefk.

47. Matveev, V. Comparison of fundamental physical properties of the model cells (protocells) and the living cells reveals the need in protophysiology. Int. J. Astrobiol., 16: 97-104 (2017).

48. Mentré, P. Water in the Cell. Masson-Dunon, Paris (1995).

49. Milo, R. \& Phillips, R. Cell Biology by the Numbers. Garland Science (2015).

50. Nakajo, N., Yoshikawa, K., Shoji, M., Ueda I. Spontaneous oscillation of artificial membrane: Equivalence in effects of temperature and volatile anesthetic. Biochem. Biophys. Res. Comm., 167: 450-455 (1990).

51. Nelson, D. L. \& Cox, M. C. Lehninger: Principles of Biochemistry $4^{\text {th }}$ edn. W H Freeman (2004).

52. Nicholls, D. G. Mitochondrial membrane potential and aging. Aging Cell 3: 35-40 (2004).

53. Okur, H. I. et al. Beyond the Hofmeister series: Ion-specific effects on proteins and their biological functions. J. Phys. Chem. B. 121, 1997-2014 (2017).

54. Parashar, A. et al. Cyanide does more to inhibit heme enzymes, than merely serving as an active-site ligand. Biochem. Biophys. Res. Commun. 455, 190-193 (2014).

55. Parashar, A., Gideon, D. A., Manoj, K. M. Murburn concept: a molecular explanation for hormetic and idiosyncratic dose responses. Dose Response 16, 1559325818774421 (2018).

56. Parashar, A. \& Manoj, K. M. Murburn precepts for cytochrome P450 mediated drug/xenobiotic metabolism. (In Press) Curr. Drug Metab. (2021). doi: 10.2174/1389200222666210118102230

57. Pedersen, J. T. \& Palmgren, M. Why do plants lack sodium pumps and would they benefit from having one? Functional Plant Biology 44, 473-479 (2017).

58. Pollack, G. H. Cells, Gels and the Engines of Life. Ebner and Sons Publisher, Seattle. (2001).

59. Przybylski, A. T., Stratten, W. P., Syren, R. M., Fox, S. W. Membrane, action, and oscillatory potentials in simulated protocells. Die Naturwissenschaften, 69: 561-563 (1982).

60. Przybylski, A. T., Fox, S. W. Excitable artificial cells of proteinoid. Appl. Biochem. Biotechnol. 10:301-307 (1984).

61. Przybylski, A. T. Excitable cell made of thermal proteinoids. Biosystems 17: 281-288 (1985).

62. Reza, M. E., Rashid, M. A., Haque, M., Pervin, F., Ali, L. Serum and intracellular levels of ionized sodium, potassium, and magnesium in type 2 diabetic subjects. Int. J. Nutr. Pharmacol. Neurol. Dis. 5:69-74 (2015).

63. Scott, J. A. \& Rabito, C. A. Oxygen radicals and plasma membrane potential. Free Rad. Biol. Med. 5; 237-246 (1988).

64. Stoin, U., et al. In situ generation of superoxide anion radical in aqueous medium under ambient conditions. Chemphyschem. 14; 4158-4164 (2013).

65. Tamagawa, H. \& Ikeda, K. Another interpretation of Goldman-Hodgkin-Katz equation based on the Ling's adsorption theory, H. Tamagawa, K. Ikeda, Euro. Biophys, J., 47: 869-879 (2018).

66. Tamagawa, H. Mathematical expression of membrane potential based on Ling's adsorption theory is 
approximately the same as the Goldman-Hodgkin-Katz equation, J. Biol. Phys., 45: 13-30 (2018).

67. Tamagawa, H., Fukai, H., Ikeda, K, Mulembo, T. Spontaneous potential spike induction across the nonliving separator intervening two electrolytic solutions, Ionics, 26: 1989-2002 (2019).

68. Toko, K., Yoshikawa, K., Tsukiji, M., Nosaka, M, Yamafuji, K. On the oscillatory phenomenon in an oil/water interface. Biophys. Chem., 22: 151-158 (1985).

69. Vaughan, G., Przybylski, A. T., Fox, S. W. Thermal proteinoids as excitability-inducing materials. BioSystems 20: 219-223 (1987).

70. Villegas, J., Villegas, L., Villegas, R. Sodium, potassium and chloride concentrations in the Schwann cell and axon of the squid nerve fiber. J. Gen. Physiol. 49:1-7 (1965).

71. Voet, D. \& Voet, J. G. Biochemistry $4^{\text {th }}$ edn. Wiley (2011).

72. Yoshikawa, K. \& Matsubara, Y. Spontaneous oscillation of electrical potential across organic ligquid membranes. Biophys. Chem., 17: 183-185 (1983).

73. Yoshikawa, K., Sakabe, K., Matsubara, Y., Ota, T. Oscillation of electrical potential in a porousmembrane doped with glycerol alpha-monooleate induced by an $\mathrm{Na}^{+} / \mathrm{K}^{+}$concentration gradient. Biophys. Chem., 20:107-109 (1984).

74. Yoshikawa, K., Sakabe, K., Matsubara, Y., Ota, T. Self-excitation in a porous membrane doped with sorbitan monooleate (Span-80) induced by an $\mathrm{Na}^{+} / \mathrm{K}^{+}$concentration gradient. Biophys. Chem., 21: 3339 (1985a).

75. Yoshikawa, K., Jinkoumaku ni yoru Bunshininshiki - Jirei hasshin genshou no ouyou - in Japanese (Molecular recognition by an artificial membranes - An application of spontaneous potential oscillation -). Maku in Japanese (Memebrane) 10: 337-348 (1985b).

76. Yoshikawa, K., Omochi, T., Matsubara, Y., Kourai, H. A possibility to recognize chirality by an excitable artificial liquid membrane. Biophys. Chem., 24: 111-119 (1986a).

77. Yoshikawa, K., Omochi, T., Matsubara, Y. Chemoreception of sugars by an excitable liquid membrane. Biophys. Chem., 23: 211-214 (1986b).

78. Yoshikawa, K., Shoji, M., Nakata, S., Maeda, S. An Excitable Liquid Membrane Possibly Mimicking the Sensing Mechanism of Taste. Langmuir 4: 759-762 (1988). 